Doi: 10.32481/djph.2021.09.018

\title{
Scams and Exploitation:
}

\section{A Growing Hazard for Delaware's Older Population}

\author{
Craig Weldon; ${ }^{1}$ Jack Berlin, $\mathrm{DO}^{2}$
}

\section{Chief Special Investigator, Investor Protection Unit, Delaware Department of Justice}

2. ChristianaCare

You wake one morning, get a cup of coffee, and sit down at your computer. You open your email and there it is: an email telling you that you purchased a brand-new iPhone and to call this number immediately if this is a mistake. You do, and it is done. You have just become a victim of a scam.

Internet scams are flourishing in the pandemic as people are increasingly working remotely and online more frequently. People working from home, the elderly, and those seeking

companionship are easy prey for online bandits. Particularly, as the population ages and the Baby Boomer generation advances into retirement, the prevalence of dementia or cognitive impairment is increasing and providing scammers with vulnerable marks for their cons. According to a metaanalysis by the American Academy of Neurology, 6.7\% of adults between the ages of 60-64 are already demonstrating mild cognitive impairment and decline greater than that of normal aging. Further to that, the incidence of dementia doubles every 10 years after the age of 60 , as one in seven adults over the age of 70 has dementia and over $25 \%$ of adults over the age of 80 have at least mild cognitive impairment.

All of this presents scammers with fertile ground to plant their scam seeds. Speaking quickly and fluidly, the scammers will especially prey on the elderly, seizing upon both seniors' unfamiliarity with the internet as well as any cognitive decline. Fraudsters will utilize the complexity of computers and cell phones to disorient and confuse their victims, often leading to panic and eventual surrender of personal and financial information.

According to the FBI, there were a reported 18,077 cases of larceny in Delaware in 2019 alone. Of those cases 1,183 were victims over the age of 60 . The report does not break down elder fraud, but the FBI does report that of those 18,077 crimes, 301 of them involved confidence, swindle, and false pretense. Likely, that is a conservative estimate with the actual number of scams being much higher.

Further to that, those seeking companionship increasingly turn to websites to meet each other. These websites offer little to no protection for users' personal information and make it extremely easy for scammers to mask their true identity. Scammers frequently validate their fraudulent profiles by impersonating people whose identities are easily verified with basic internet searches. The scammers typically try to move from the website to a direct form of communication, be it text message or personal email, as quickly as possible.

Even after a scam is identified, reporting can be an obstacle. Embarrassment is often an overwhelming emotion for victims once they realize they have been scammed. Too often the question of "Who can help me?" takes a back seat to "What will they think?" Depending on how long the scams last, the financial losses can be devastating. Reports of suspected financial exploitation in the past three years have reveal losses ranging from a couple hundred dollars to hundreds of thousands of dollars, ruining victims' lives. 
Several types of scams have become particularly prevalent during the pandemic:

\section{Romance/Relationship Scams}

These are among the most elaborate and manipulative scams we see. The scam begins when an unsuspecting victim creates a profile on any one of the many websites dedicated to connecting people (e.g., OurTime.com, Match.com, ChristianMingle.com, etc.). In most instances the scammer has also created a profile, which is completely fake but may be based on a real person they have researched on the internet. The scammer then searches and will try to make connections with specific "matches."

Scammers look at this like fishing: throw as many lines into the water as you can and something will bite. Once a connection is made, the scammer quickly moves the communication away from the online site and to a more one-on-one setting. He will want to solidify the connection and will be very responsive to any communication they receive.

After several days of communication, the scammer will invent a situation where they urgently need help due to unforeseen circumstances - often, he tells the victim that he is overseas and does not have access to funds needed to rectify an emergency like an arrest or a lost passport. These stories can be elaborate and may seem farfetched to an outside observer, but they are completely believable to a victim who has become invested in the person he thinks he is speaking to.

The scammer will ask to have the funds sent to a local "friend" who can deliver it to them or in the form of gift cards. Alternatively, he may ask the connection to open an account at an international bank. Each time he successfully takes money from the victim, the scammer becomes more invested - knowing that his scam works, the scammer becomes focused on how to take as much as they can before the victim either runs out of money or discovers the truth. Even when the scammer feels like he may be losing the connection, he will attempt to guarantee payment as much as possible. The scammer will only stop when he feels he cannot extract any more from the victim - or when a law enforcement agency gets involved.

\section{Lottery Scams}

These scams begin when an email or text message alerts the recipient that he is the winner of a lottery or sweepstakes. All the "winner" must do is contact the sender, and all details will be revealed. Once that happens, the scammer will usually inform the victim that he needs to pay taxes on the winnings before any funds can be released. As in other scams, the scammer will speak quickly to confound or confuse his victim. He will tell of grand presentations and promise gifts when the winnings are presented. If the victim appears at all skeptical, the scammer will convey urgency (i.e., by claiming that the victim will pay higher and higher fees the longer they wait).

\section{Package Scams}

These scams tell the recipient that a recent purchase is in transit and instructs them to click on a hyperlink to track the delivery. In reality, the link gives the scammer access to the victim's computer or cell phone (e.g., by downloading malware). Once the scammer has breached the victim's device, he will attempt to steal sensitive data including usernames and passwords. 
Doi: $10.32481 /$ djph.2021.09.018

\section{Grandparent Scams}

Notably on the rise recently, these scams occur when a caller identifies himself as a relative, usually calling a grandparent and telling them they were away and needed funds immediately. The reason given for the immediate need for funds include car accidents, arrests for questionable crimes, or owing a bill.

This particular scam hits very close to home for me: one day in my office at the Department of Justice, a coworker received a cell phone call that his son was in trouble and needed money right away. This coworker became so upset that he panicked and unfortunately began to fall prey to the scammer. It was not until I heard his concern that I made him slow down and ask the right questions. At the same time, I called his son, who unsurprisingly was in his apartment studying. Thankfully my coworker realized what was going on and hung up the phone, however he was nearly one of the countless people who have fallen victim to these scams.

I am not singling out this coworker to pick on him - he is not a gullible or stupid person. As a DOJ employee, he knows much of the information I am sharing here. But he is also a father, and parents will understand that love for our children overrides every other thought in our minds. I share his experience because it underscores how these scams prey on our emotions and cause us, even the most vigilant, to suspend rational thought, become careless, and make bad decisions.

So now you know the scams and why they succeed. What do you do if you become a victim? How do you get out of a bad situation?

The easiest way to avoid any of these nightmares is to remember the tried-and-true adage: if something sounds too good to be true, it probably is. Still if you do find yourself lured into a trap, time is of the essence. The sooner you can get out of it, the better off you are. Talking to a trusted friend, relative or authority may shed the light you need to see the whole picture. I also recommend a basic internet search to verify facts, independently contact the companies that scammers claim to represent, and learn whether other people have been scammed by similar calls.

Several agencies and websites offer excellent resources that explain these crimes and offer tips, including:

- www.FBI.gov

- $\underline{w w w . S t o p F r a u d . g o v}$

- www.IC3.org

- www.ftc.gov

- de.gov/consumer

I have spoken with several victims who have gone as far as changing their phone numbers, canceling phone contracts, and placing call blocks on their systems. Nonetheless, in my experience, once you are victimized, scammers will continue contacting you despite any drastic measures taken. I had a case in the Newark area where the scammers sent a pizza to the house with a note asking the homeowner to call them.

Unfortunately, scammers are increasingly sophisticated and get better each year at covering their tracks. Getting law enforcement involved early may not mean that the scammers are caught quickly - but it does give a chance to share the information with other partners and to help other 
people avoid becoming victims. The IC3 (Internet Crimes Complaint Center) acts as the FBI's clearinghouse for scam cases; all of the data shared in IC3 gets reviewed by investigators, who can analyze the information about each case and establish patterns and connections that allow federal and state law enforcement to stop these crimes from reoccurring. These connections help agents across the U.S. - and across the world - compile similar data to build much larger cases. As one example, a Delaware victim of a romance scam in Delaware reported what happened to her and was ultimately able to testify at a sentencing hearing for her scammer in the State of New York.

Keeping up with scammers is full-time work. They craft their scams to adapt to a changing world, and when opportunities appear they pivot and create new scams. It can be tempting to succumb to shame if you become a victim, but there is nothing to be ashamed of - by sharing your stories and communicating openly about them, you help us all benefit and prevent others from becoming victims. Stay diligent and work with all our partners in slowing the financial abuse of our elder population.

Copyright (c) 2021 Delaware Academy of Medicine / Delaware Public Health Association.

This is an Open Access article distributed under the terms of the Creative Commons Attribution Non-Commercial License (https://creativecommons.org/licenses/by-nc-nd/4.0/) which permits unrestricted non-commercial use, distribution, and reproduction in any medium, provided the original work is properly cited. 